\title{
Simultaneously Enhanced Singlet Oxygen and Fluorescence Production of Nanoplatform by Surface Plasmon Resonance Coupling for Biomedical Applications
}

Fenxiang Hong, ${ }^{\#, \dagger}$ Chu Tang,,${ }^{\#}$ Qilu Xue, ${ }^{\dagger}$ Lei Zhao, ${ }^{\dagger}$ Hongyan Shi, ${ }^{*},+$, Bo Hu,,${ }^{*} \dagger$ Xianghan Zhang, ${ }^{*} \dagger$

†School of Life Science and Technology, Library, Xidian University, Xi’an 710126, Shaanxi, P.R. China. E-mail: hyshi@xidian.edu.cn; bohu@xidian.edu.cn; xhzhang@xidian.edu.cn

$\ddagger$ Kunpad Communication Pty. Ltd. , Kunshan 215300, Jiangsu, P.R. China

\#These authors contributed equally to this work. 

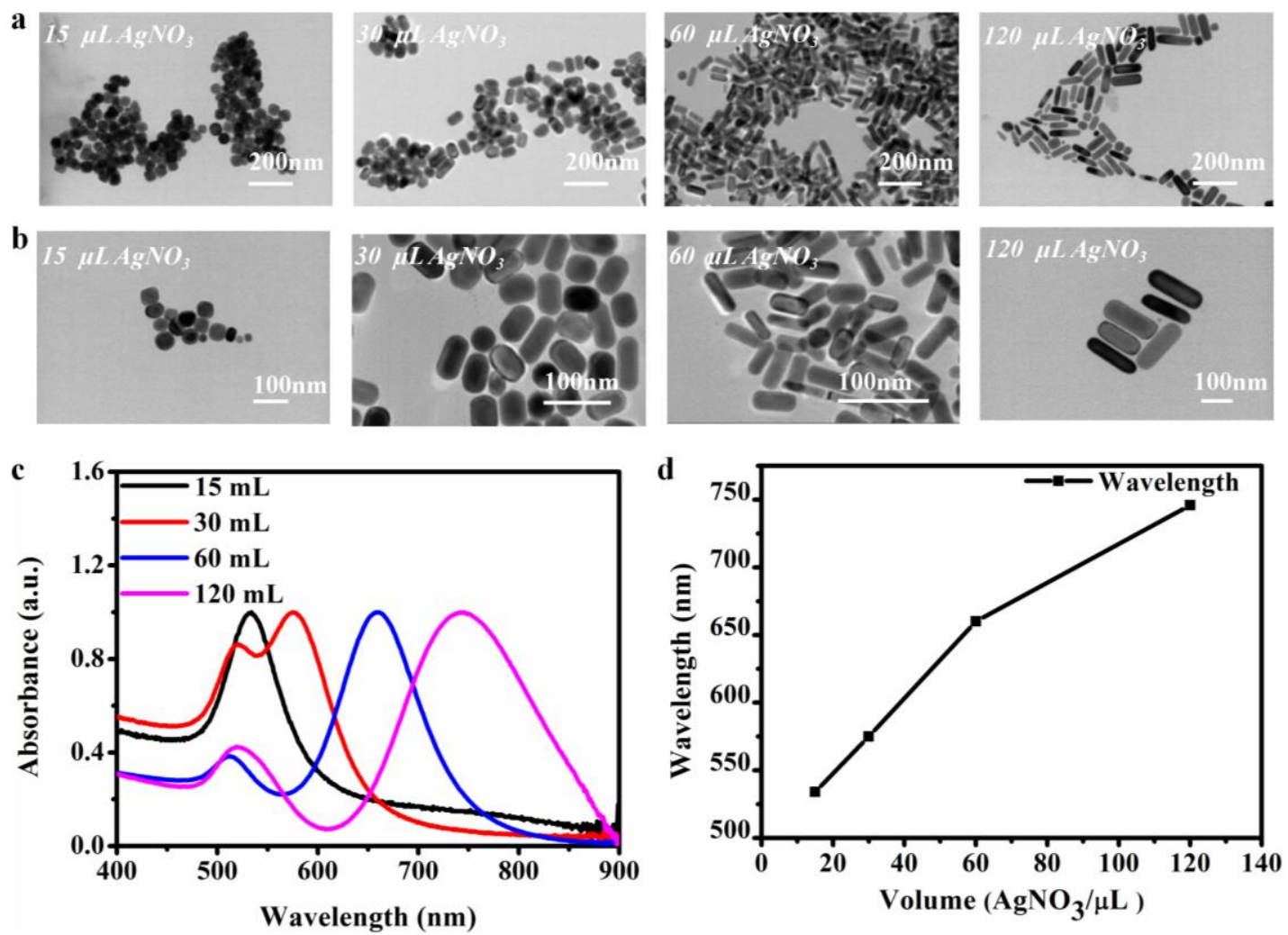

Figure S1. Optical characterization and TEM images of the AuNRs. (a) UV-Vis absorbance spectra of AuNRs were synthesized by different volumes of silver nitrate; (b) UV-Vis absorbance peaks of AuNRs were synthesized by different volumes of silver nitrate: $534 \mathrm{~nm}\left(15 \mu \mathrm{L} \mathrm{AgNO}_{3}\right), 575 \mathrm{~nm}\left(30 \mu \mathrm{L} \mathrm{AgNO}_{3}\right), 660 \mathrm{~nm}\left(60 \mu \mathrm{L} \mathrm{AgNO}_{3}\right)$, and $746 \mathrm{~nm}\left(120 \mu \mathrm{L} \mathrm{AgNO}_{3}\right)$. (c) (d) TEM images of AuNRs having UV-Vis spectra wavelengths between 530 and $750 \mathrm{~nm}$, arranged in the order of increasing aspect ratio from (c) and (d) left to right. Insets are the volume of silver nitrate.

a<smiles>C=Cc1c(C)c(=Cc2nc3c(c(C(=O)O)c2C)=N[C@@H](CCC(=O)O)C=3CC(=O)O)[nH]c1=Cc1[nH]c(C=C2N=C(CC)C(C)=C2C)c(CC)c1C</smiles>

b

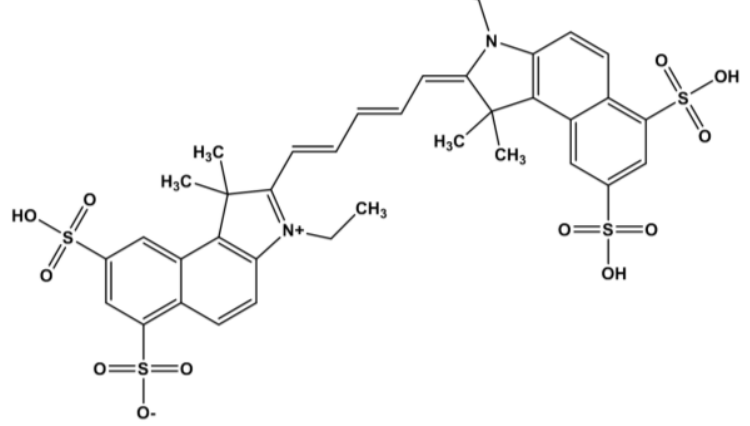

Figure S2. Structures of (a) photosensitizer Ce6 and (b) fluorophore Cy5.5. 

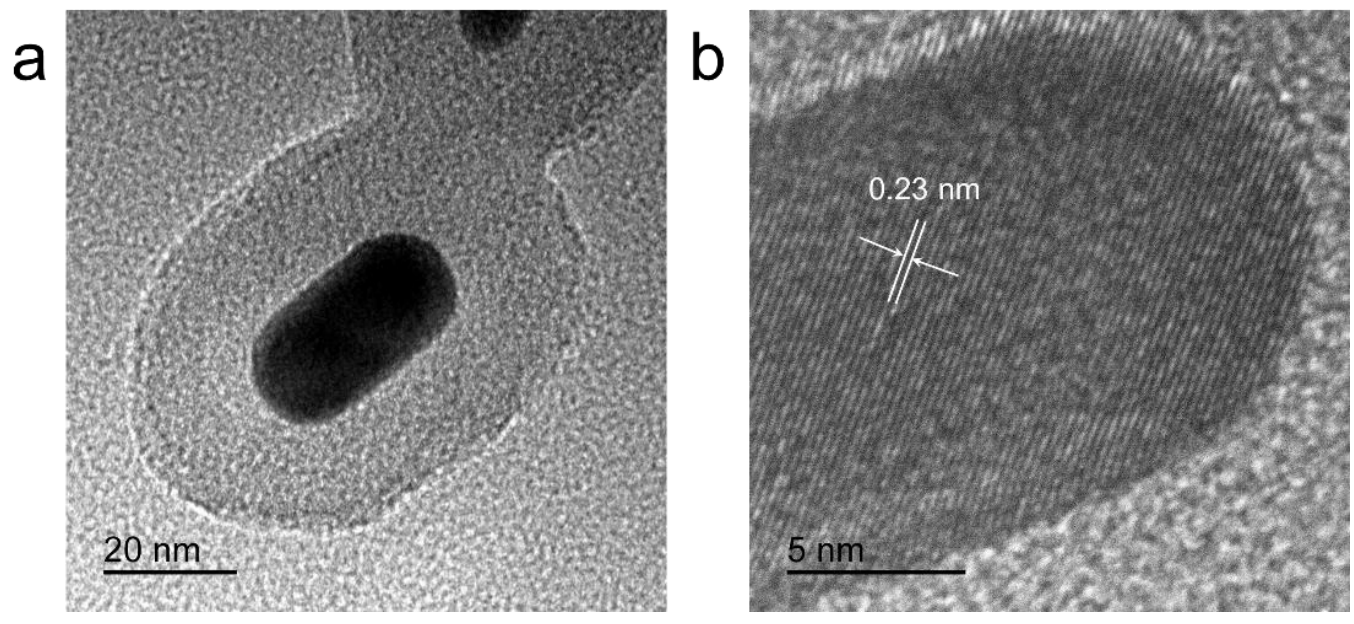

Figure S3. HRTEM images of AuNR@ mSiO $2-C e 6-C y 5.5$.

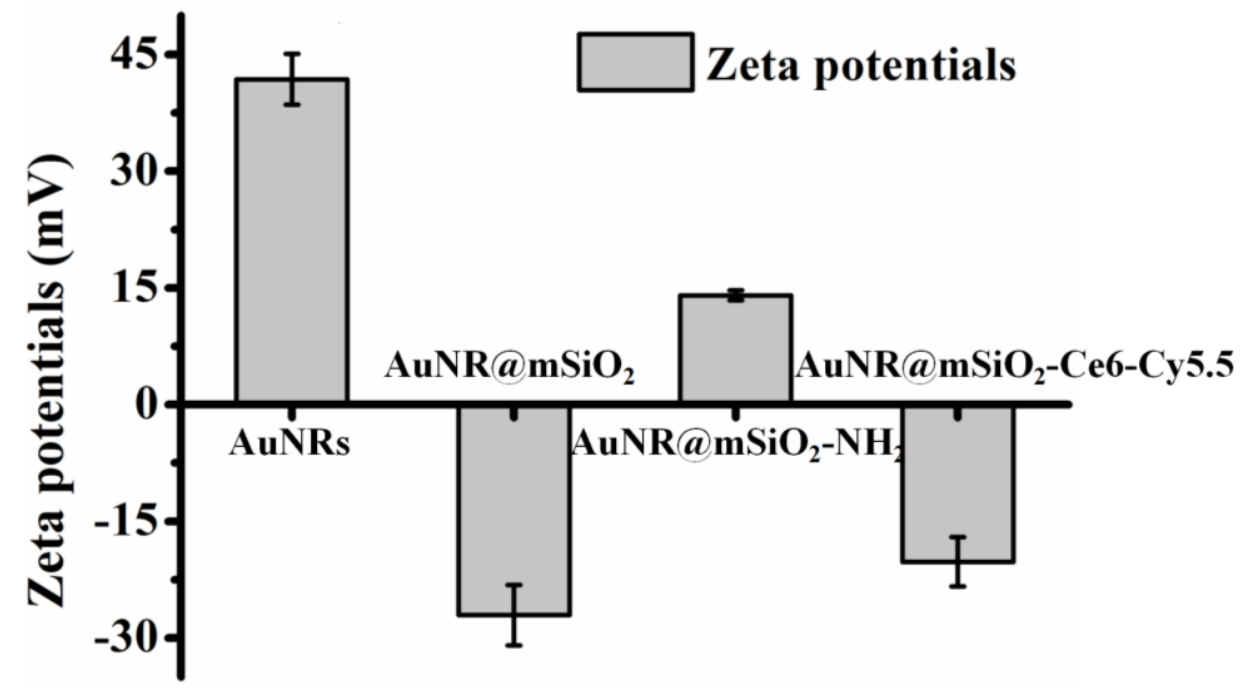

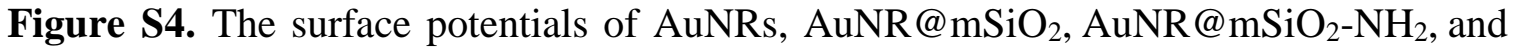
AuNR@mSiO2-Ce6-Cy5.5. 


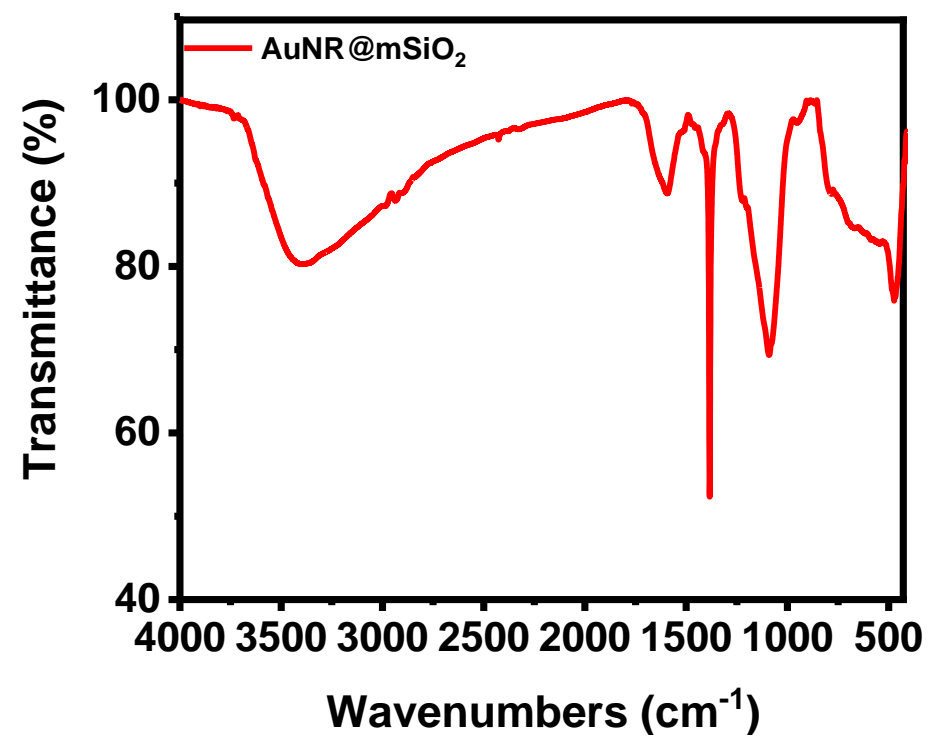

Figure S5. FT-IR spectra of AuNR@ $\mathrm{mSiO}_{2}$.

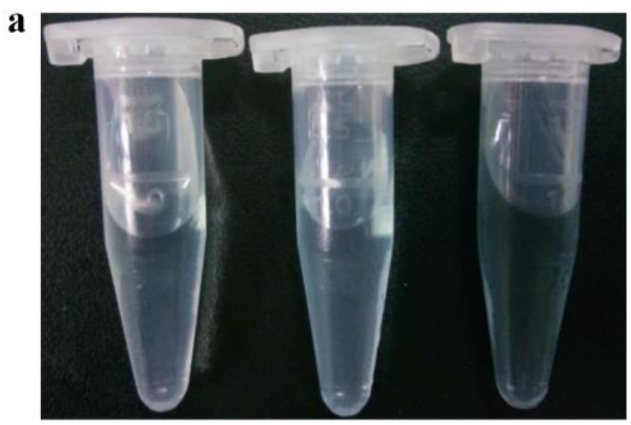

b

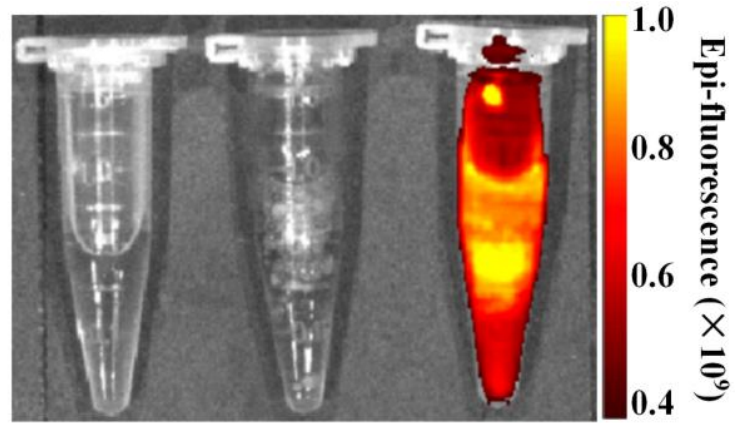

Figure S6. Fluorescence map of AuNRs, AuNR@ $\mathrm{mSiO}_{2}$ and $\mathrm{AuNR} @ \mathrm{mSiO}_{2}-\mathrm{Ce} 6-\mathrm{Cy} 5.5$ (left to right), (a) Bright field, (b) Dark field. 


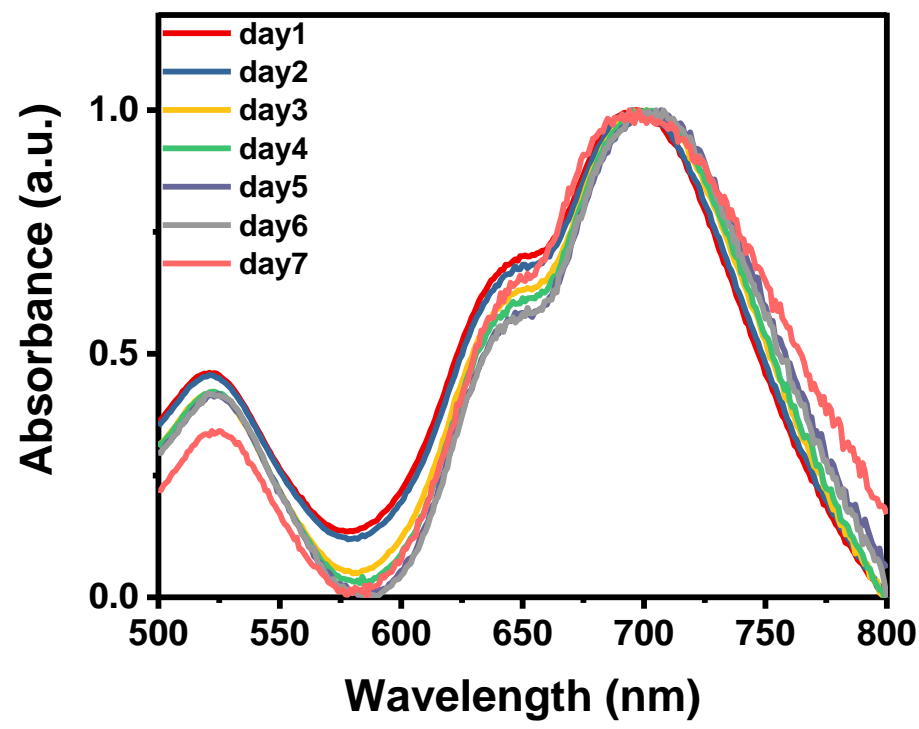

Figure S7. Normalized UV-Vis absorbance spectra of AuNR@ $\mathrm{mSiO}_{2}-\mathrm{Ce} 6-\mathrm{Cy} 5.5$ after saving different time.

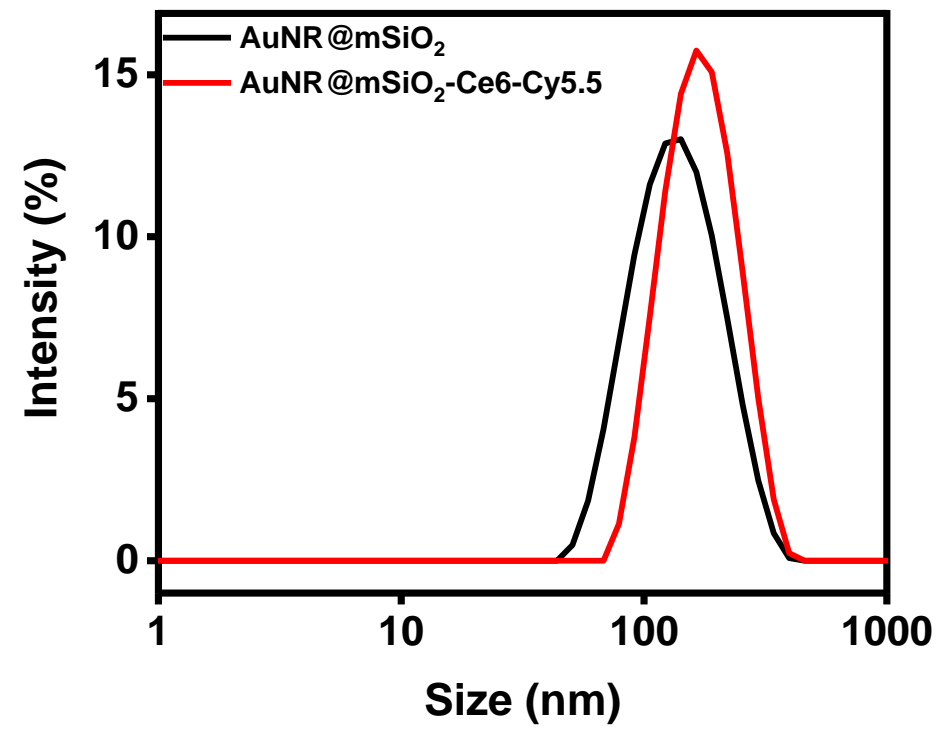

Figure S8. Representative size of AuNR @ mSiO 2 (black) and AuNR @ mSiO $2-C e 6-C y 5.5$ (red) measured by dynamic light scattering. 

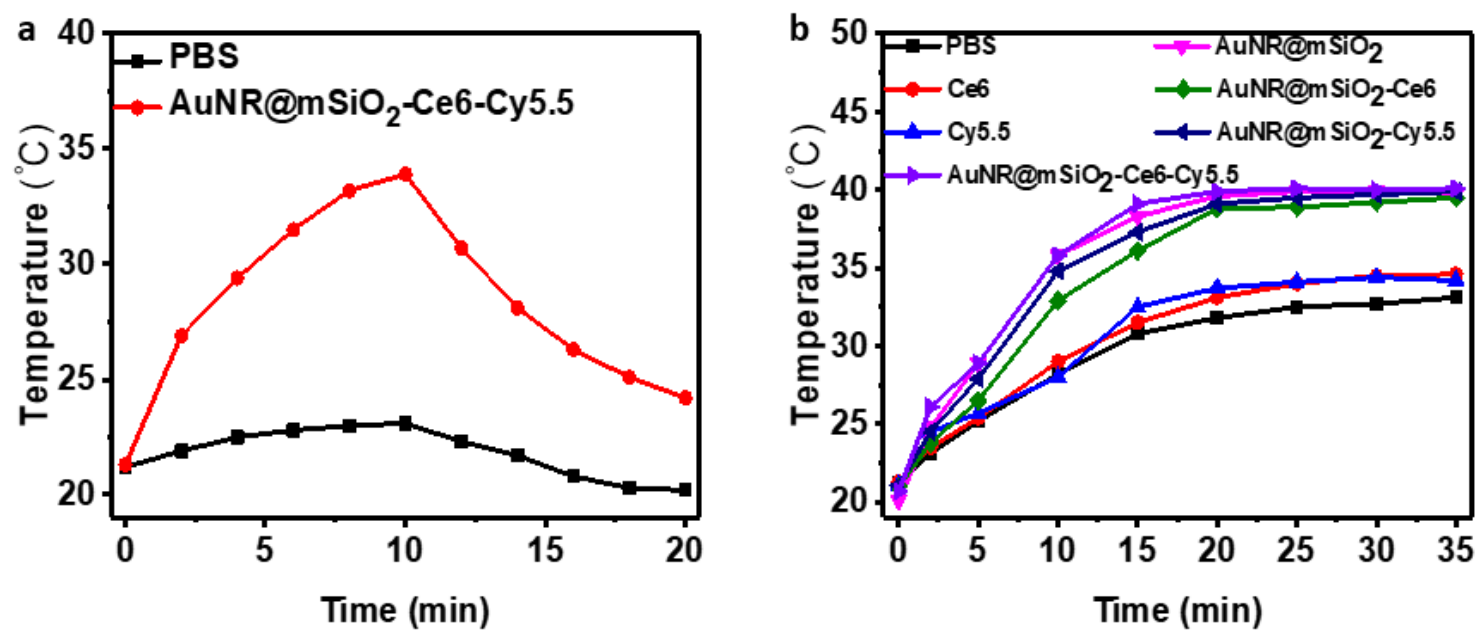

Figure S9. The photothermal effects. (a) The temperatures curve of AuNR@ $\mathrm{SiO}_{2}-\mathrm{Ce} 6-$ Cy5.5 $(100 \mu \mathrm{g} / \mathrm{mL})$ and PBS solution under laser irradiation laser ON/OFF $\left(1.0 \mathrm{~W} / \mathrm{cm}^{2}\right)$. (b) Photothermal effect ofAuNR@ $\mathrm{SiO}_{2}-\mathrm{Ce} 6-\mathrm{Cy} 5.5$ at different concentrations under $10 \mathrm{~min}$ laser irradiation $\left(808 \mathrm{~nm}, 1.0 \mathrm{~W} / \mathrm{cm}^{2}\right)$.
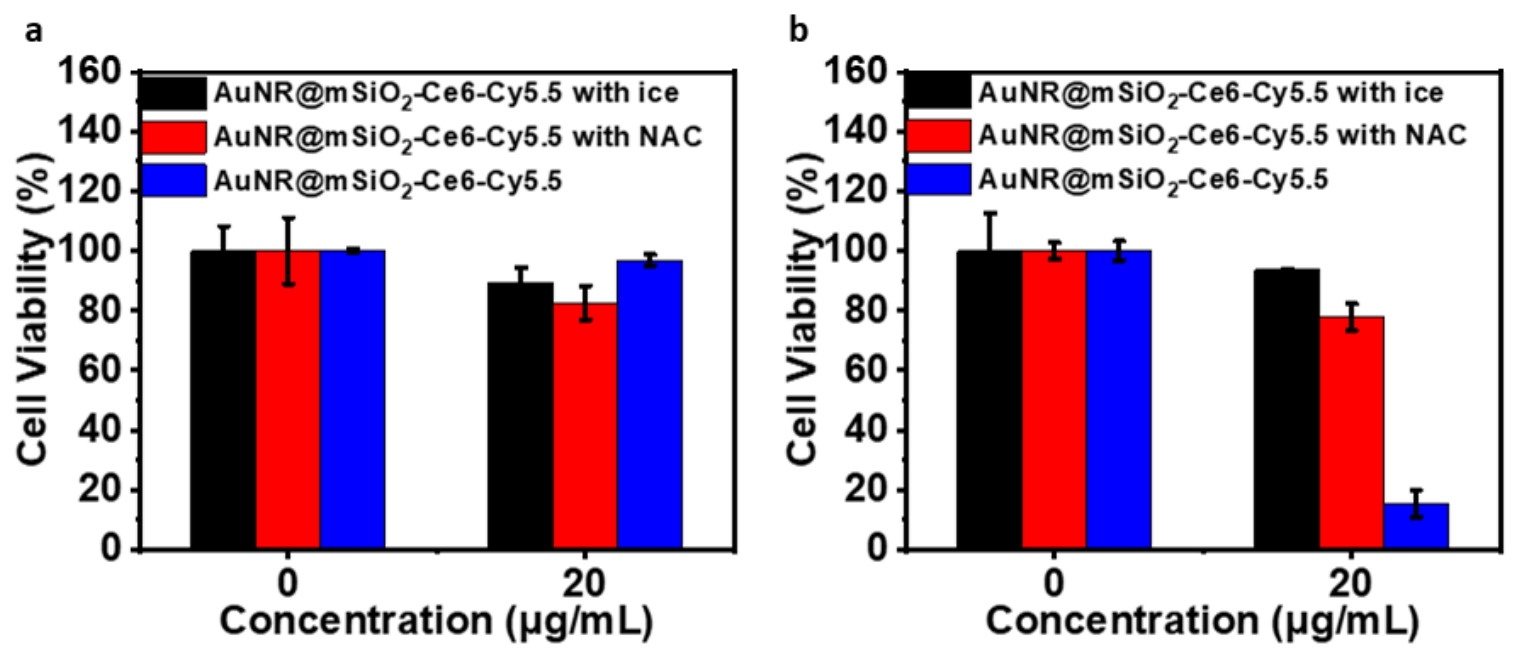

Figure S10. (a) Cell viability of $4 \mathrm{~T}-1$ cells treated with different concentrations of AuNR@mSiO 2 -Ce6-Cy-5.5 with ice, AuNR@mSiO 2 -Ce6-Cy-5.5 with NAC (3 mM), and AuNR@mSiO $2-C e 6-C y-5.5$ without laser irradiation(n=3). (b) Cell viability of 4T-1 cells treated with different concentrations of AuNR@mSiO $2-\mathrm{Ce} 6-\mathrm{Cy}-5.5$ with ice, AuNR@mSiO 2 -Ce6-Cy-5.5 with NAC (3 mM), and AuNR@ mSiO 2 -Ce6-Cy-5.5 under laser irradiation $(n=3)$. 